\title{
LSD1 Inhibitor CC-90011
}

National Cancer Institute

\section{Source}

National Cancer Institute. LSD1 Inhibitor CC-90011. NCI Thesaurus. Code C131303.

An orally available inhibitor of lysine specific demethylase 1 (LSD1), with potential antineoplastic activity. Upon administration, CC-90011 binds to and inhibits LSD1, a demethylase that suppresses the expression of target genes by converting the di- and mono-methylated forms of lysine at position 4 of histone H3 (H3K4) to mono- and unmethylated H3K4, respectively. LSD1 inhibition enhances H3K4 methylation and increases the expression of tumor (remove hyphen) suppressor genes. This may lead to an inhibition of cell growth in LSD1-overexpressing tumor cells. In addition, LSD1 demethylates mono- or di-methylated H3K9 which increases gene expression of tumor promoting genes; inhibition of LSD1 promotes H3K9 methylation and decreases transcription of these genes. LSD1, an enzyme belong ing to the flavin adenine dinucleotide (FAD)-dependent amine oxidase family that is overexpressed in certain tumor cells, plays a key role in tumor cell growth and survival. 